DOI: 10.20472/IAC.2019.045.042

\author{
ILONA TOMASZEWSKA \\ Warsaw School of Economics, Poland, Poland
}

\title{
UNDERWRITING FACTORS IN MOTOR INSURANCE.
}

\begin{abstract}
:
Underwriting is an important element of the assessment and valuation process of insurance risk. The aim of this process is the proper construction of the insurance portfolio by defining criteria indicating the risk appetite by the insurer, at the same time having a real impact on the technical result. Each insurance company specifies its own guidelines on risk tolerance, both regarding the entity and the subject of insurance. What variables are taken into account when determining the risk parity depends on the strategy adopted by the management of the company, guidelines defined within the capital group or simply by the risk appetite. Less restrictive or even other set of parameters is determined if the purpose of the insurance company is to achieve the highest possible gross written premium, understood as collecting the highest value of premium and volume of customers. Other parameters will be considered when the insurance company focuses on achieving a certain profitability index. Still others, when the purpose of the company is to diversify the vehicle portfolio and, for example, to open up to more expensive vehicles.

The aim of the study is to show how important for motor insurance is underwriting process conducted by the insurer, what are its elements for MTPL as for casco, and how underwriting process affects the quality of the insurance company's portfolio.
\end{abstract}

\section{Keywords:}

underwriting, motor insurance, referrals, policy, risk

JEL Classification: G22 